Research Article

\title{
Characterizing Patients with Uncontrolled Blood Pressure at an Urban Hospital in Hanoi, Vietnam
}

\author{
Hoang Thanh Nguyen $\mathbb{D}^{1},{ }^{1}$ Nam Hoang Thi Phuong, ${ }^{1,2}$ Ngoc Tran Nguyen, ${ }^{1,3}$ \\ Tuan Nguyen Anh, ${ }^{1,4}$ and Vung Nguyen Dang ${ }^{1}$ \\ ${ }^{1}$ Hanoi Medical University, Hanoi, Vietnam \\ ${ }^{2}$ National Geriatric Hospital, Hanoi, Vietnam \\ ${ }^{3}$ National Institute of Mental Health, Bach Mai Hospital, Hanoi, Vietnam \\ ${ }^{4}$ Viet Duc University Hospital, Hanoi, Vietnam \\ Correspondence should be addressed to Hoang Thanh Nguyen; nguyenht.hmu@gmail.com
}

Received 5 June 2020; Revised 25 July 2020; Accepted 29 August 2020; Published 10 September 2020

Academic Editor: Tomohiro Katsuya

Copyright ( 92020 Hoang Thanh Nguyen et al. This is an open access article distributed under the Creative Commons Attribution License, which permits unrestricted use, distribution, and reproduction in any medium, provided the original work is properly cited.

Great efforts to advance the diagnosis and treatment of hypertension for controlling hypertension have been made; however, the rates of uncontrolled blood pressure are still high. This study explored the rate of uncontrolled hypertension in patients with hypertension managed in an urban hospital of Vietnam and identified associated factors. A cross-sectional survey was performed from August to October 2019 among hypertensive patients at an urban hospital in Hanoi, Vietnam. Blood pressure was evaluated at the time of medical examination. Demographic, clinical, and behavioral characteristics were also collected. Multivariate logistic regression was used to identify the factors related to uncontrolled hypertension. Among 220 patients, the rate of uncontrolled hypertension was $40.5 \%$. Females had a lower likelihood of having uncontrolled hypertension compared to males (adjusted $\mathrm{OR}=0.33 ; 95 \% \mathrm{CI}=0.11-0.98$ ). Higher duration of diseases (adjusted $\mathrm{OR}=1.07 ; 95 \% \mathrm{CI}=1.01-1.14$ ) and higher body mass index (adjusted $\mathrm{OR}=1.23$; 95\% $\mathrm{CI}=1.05-1.45$ ) were positively associated with uncontrolled hypertension. Patients who carried supplies needed for self-care, cut down on stress, exercised regularly, and stopped/cut down on smoking were also less likely to develop uncontrolled hypertension. This study reveals that uncontrolled hypertension was common among hypertensive patients in Vietnam. Improving self-care capacity and encouraging healthy behaviors are critically important to control blood pressure, particularly among patients who were males and had high disease duration and body mass index.

\section{Introduction}

High blood pressure, or hypertension, has been well recorded as a leading cause of morbidity and mortality in both developed and developing nations. People with hypertension are particularly vulnerable to cardiovascular diseases (CVDs), stroke, or renal failures [1]. It is estimated that the global prevalence of hypertension in adults is $30.8 \%$ [2]. Great efforts to advance the diagnosis and treatment of hypertension for controlling hypertension have been made; however, the rates of uncontrolled blood pressure are still high $[1,3,4]$, especially in Asian countries. Prior literature in China and Japan indicated that among hypertensive patients receiving treatment, uncontrolled hypertension was observed in $62.5 \%$ and $62.9 \%$ of hypertensive patients, respectively $[2,5]$, while these rates in the United States (US) and the United Kingdom (UK) were 31.1\% and 39.2\%, correspondingly [2]. A report from the World Health Organization revealed that more than one billion people are experiencing uncontrolled hypertension worldwide [6]. Many factors have been found that are attributed to this condition, consisting of clinical (e.g., gender, age, duration of diseases, comorbidities, and nonadherence to medication) and behavioral factors (e.g., unhealthy and sedentary lifestyles) [7-9]. However, these risk factors are varied and inconsistent among studies. Given the severe consequences of uncontrolled hypertension $[10,11]$, attempts to identify risk factors for this condition are important to make it understandable, which helps to design appropriate management strategies in clinical settings. 
Vietnam has been witnessed a rapid epidemiological transition in the last decade, resulting in a significant increase in noncommunicable diseases, including hypertension [12]. A recent meta-analysis figured out that $21.1 \%$ of Vietnamese adults are living with hypertension [13]. To date, only one study performed in the community found that $37.7 \%$ of patients who received antihypertensive medication developed uncontrolled blood pressure [14]. However, studies to investigate thoroughly the determinants of uncontrolled blood pressure in hospital-based settings are insufficient. This study explored the rate of uncontrolled hypertension in patients with hypertension managed in an urban hospital of Vietnam and identified associated factors.

\section{Materials and Methods}

2.1. Study Design and Sampling Method. A cross-sectional survey was performed from August to October 2019 among hypertensive patients at an urban hospital in Hanoi, Vietnam. This hospital currently managed approximately two thousand hypertensive patients living and working in Hanoi, Vietnam. Participants were eligible for the study if they had been confirmedly diagnosed to suffer from hypertension according to the guideline of Vietnam Ministry of Health (persistently systolic blood pressure level of $\geq 140 \mathrm{mmHg}$ and/or persistently diastolic blood pressure level of $\geq 90 \mathrm{mmHg}$ ). Moreover, participants had to be at least 18 years old, registered to manage and treat hypertension in the hospital. We excluded patients who (1) had impaired cognitive conditions and (2) were inpatients or hypertensive patients without registration of chronic disease management at the hospital. Among 250 patients who were invited to participate in the study, a total of 220 patients (response rate $88 \%$ ) agreed to be enrolled in the survey.

2.2. Data Collection and Measurement. Data collection was carried out by undergraduate medical students from Hanoi Medical University. They were trained carefully in communication skills with patients as well as manners to collect data consistently. Patients were invited when they finished all procedures (e.g., examining medical conditions, having a blood test, and receiving drug prescription) and waited for medication dispense. If they were willing to participate, they were invited to a private counseling room for an interview and to protect their privacy. Patients have informed briefly the purpose of the study as well as their benefits. After completing the survey, their weight and height were measured.

2.2.1. Primary Outcome. Office blood pressure was evaluated by using the Japanese Alpk2 sphygmomanometer at the time of medical examination. Blood pressure was measured twice; the second measure was done 10 minutes after the first measure. The mean of the two measures was used for analysis. Uncontrolled hypertensive patients were defined as those having a systolic blood pressure level of $\geq 140 \mathrm{mmHg}$ and/or diastolic blood pressure level of $\geq 90 \mathrm{mmHg}$ according to the guideline of Vietnam Ministry of Health; otherwise, they were classified as controlled hypertensive patients.

2.2.2. Covariates. During the interview, patients were asked to report their sociodemographic and behavioral characteristics (e.g., education, occupation, living area, smoking status, and alcohol drinking). Weight, height, and body mass index were measured after completing the survey. Other demographic and clinical covariates such as age, gender, comorbidities, number of antihypertensives used, last lowdensity lipoprotein (LDL), last high-density lipoprotein (HDL), and last triglyceride measures were extracted from the electronic medical record system of the hospital. We also employed eight items from the Condition-specific Recommendations and Adherence scale to evaluate the frequency of different recommended health behaviors for hypertensive patients [15]. These behaviors included the following: (1) take prescribed medication daily, (2) follow a low-salt diet, (3) follow a low-fat diet, (4) exercise regularly, (5) stop/cut down on smoking, (6) cut down on alcohol, (7) cut down on stress, and (8) carry supplies needed for self-care. Each behavior has six levels of response about frequency from 0 "none of the time" to 5 "all of the time". Those answering options 0-2 were classified into the "Nonadherence" group while other patients were identified as the "Adherence" group. The total score of this scale ranges from 0 to 40 , in which patients having $32 / 40$ points were categorized as "overall health behavior adherence"; otherwise, they were categorized into "overall nonadherence" group [15].

2.3. Statistical Analysis. Descriptive statistics and multivariable regression models were applied in this study. Since continuous variables in this study, namely, age, duration of disease, number of comorbidities, body mass index, last lowdensity lipoprotein, last high-density lipoprotein, last triglyceride, and adherence score had nonnormal distribution, median and interquartile range were presented. Chi-squared and Mann-Whitney tests were used to examine the difference of demographic, clinical, and behavioral characteristics between controlled and uncontrolled hypertensive patients. Multivariate logistic regression, along with a stepwise forward selection strategy, was employed to identify associated factors with hypertensive conditions. The loglikelihood test was performed with a threshold of a $p$ value of less than 0.2 to select the variables. Adjusted odds ratios (OR), $p$ value, and 95\% confidence interval (CI) were revealed. The level of statistical significance was set at the $5 \%$ level.

\section{Results and Discussion}

Among 220 patients in our sample, the rate of uncontrolled hypertension was $40.5 \%$. This condition was found to be significantly higher in male patients $(48.2 \%)$ than in female one $(33.0 \%)(p<0.05)$. Meanwhile, there was no difference in the rate of uncontrolled hypertension among age, education, occupation, living location, smoking, and alcohol groups $(p>0.05)$ (Table 1$)$. 
TABLE 1: Sociodemographic characteristics of hypertensive patients.

\begin{tabular}{|c|c|c|c|c|c|c|c|}
\hline \multirow[t]{2}{*}{ Characteristics } & \multicolumn{2}{|c|}{$\begin{array}{c}\text { Controlled } \\
\text { hypertension }\end{array}$} & \multicolumn{2}{|c|}{$\begin{array}{l}\text { Uncontrolled } \\
\text { hypertension }\end{array}$} & \multicolumn{2}{|c|}{ Total } & \multirow[t]{2}{*}{$p$} \\
\hline & $n$ & $\%$ & $n$ & $\%$ & $n$ & $\%$ & \\
\hline Total & 131 & 59.6 & 89 & 40.5 & 220 & 100.0 & \\
\hline \multicolumn{8}{|l|}{ Age group } \\
\hline$<60$ years & 39 & 59.1 & 27 & 40.9 & 66 & 30.0 & 0.99 \\
\hline $60-69$ years & 56 & 60.2 & 37 & 39.8 & 93 & 42.3 & \\
\hline$\geq 70$ years & 36 & 59.0 & 25 & 41.0 & 61 & 27.7 & \\
\hline \multicolumn{8}{|l|}{ Gender } \\
\hline Male & 56 & 51.9 & 52 & 48.2 & 108 & 49.1 & 0.02 \\
\hline Female & 75 & 67.0 & 37 & 33.0 & 112 & 50.9 & \\
\hline \multicolumn{8}{|l|}{ Education } \\
\hline$<$ High school & 55 & 56.7 & 42 & 43.3 & 97 & 44.3 & 0.67 \\
\hline High school & 32 & 64.0 & 18 & 36.0 & 50 & 22.8 & \\
\hline$>$ High school & 44 & 61.1 & 28 & 38.9 & 72 & 32.9 & \\
\hline \multicolumn{8}{|l|}{ Occupation } \\
\hline Self-employed & 58 & 59.2 & 40 & 40.8 & 98 & 46.0 & 0.69 \\
\hline Retired & 56 & 62.9 & 33 & 37.1 & 89 & 41.8 & \\
\hline Others & 14 & 53.9 & 12 & 46.2 & 26 & 12.2 & \\
\hline \multicolumn{8}{|l|}{ Living location } \\
\hline Rural & 108 & 57.8 & 79 & 42.3 & 187 & 85.4 & 0.24 \\
\hline Urban & 22 & 68.8 & 10 & 31.3 & 32 & 14.6 & \\
\hline \multicolumn{8}{|l|}{ Current smokers } \\
\hline No & 114 & 59.1 & 79 & 40.9 & 193 & 87.7 & 0.70 \\
\hline Yes & 17 & 63.0 & 10 & 37.0 & 27 & 12.3 & \\
\hline \multicolumn{8}{|l|}{ Alcohol drinkers } \\
\hline No & 97 & 61.8 & 60 & 38.2 & 157 & 71.4 & 0.29 \\
\hline Yes & 34 & 54.0 & 29 & 46.0 & 63 & 28.6 & \\
\hline
\end{tabular}

Table 2 shows the clinical characteristics of the sample. The highest proportion of patients had experienced hypertension for more than five years (47.7\%) and used three medications (35.0\%). No significant difference was found between controlled and uncontrolled hypertension groups regarding the duration of diseases, number of medications, overweight/obesity status, number of comorbidities, last LDL/HDL, and last triglyceride. Uncontrolled hypertensive patients had significantly higher body mass index $($ median $=24.0, \mathrm{IQR}=[22.3-26.1])$ than controlled hypertensive group (median $=23.4, \mathrm{IQR}=$ [21.8-25.2]) $(p<0.05)$.

Meanwhile, none of the behavior was found to be significantly different between controlled and uncontrolled hypertension groups except "carrying supplies needed for self-care". The rate of uncontrolled hypertension among patients who did not carry these supplies frequently (45.4\%) was remarkably higher than their counterparts $(31.7 \%)$ $(p<0.05)$ (Table 3).

The results of multivariate logistic regression are presented in Table 4. Females had a lower likelihood of having uncontrolled hypertension compared to males $(\mathrm{OR}=0.33$; $95 \% \mathrm{CI}=0.11-0.98)$. Higher duration of diseases $(\mathrm{OR}=1.07$; $95 \% \mathrm{CI}=1.01-1.14)$ and higher body mass index $(\mathrm{OR}=1.23$; 95\% CI $=1.05-1.45)$ were positively associated with uncontrolled hypertension. Patients who carried supplies needed for self-care, cut down on stress, exercised regularly, and stopped/cut down on smoking were also less likely to develop uncontrolled hypertension.

\section{Discussion}

The present study revealed the substantially high rate of uncontrolled hypertension (40.5\%) among patients receiving antihypertensive treatment in a Vietnamese hospital. Moreover, risk factors for uncontrolled hypertensive conditions were found comprising being male, increasing body mass index, following unhealthy or sedentary lifestyles, and not preparing essential medications for self-care. This study indicated critical results that can suggest important implications for controlling hypertension in hospital settings of Vietnam.

The rate of uncontrolled hypertension among hypertensive patients in our study $(40.5 \%)$ could be comparable to the previous study performed in ten provinces of Vietnam (37.7\%) [14]. This finding was lower compared to other countries in Asia and Africa such as China (62.5\%), Japan (62.9\%) [2, 5], India (63.6\%) [16], South Africa (75.5\%) [17], Democratic Republic of the Congo (77.5\%) [18], Ghana (57.7\%) [19], and Ethiopia (52.5\%) [20], but higher than that in Thailand (24.6\%) [1], the USA (31.1\%), and the UK $(39.2 \%)$ [2]. The differences in demographic and clinical characteristics of hypertensive patients across studies regarding gender, medication adherence, body mass index, comorbidity, and behaviors (e.g., alcohol use or smoking) might be the reasons for the diversity of uncontrolled hypertension prevalence. Nonetheless, approximately half of hypertensive patients had uncontrolled blood pressure suggesting urgent needs of comprehensive management strategies to address this issue and improve patients' health outcomes. 
TABle 2: Clinical characteristics of hypertensive patients.

\begin{tabular}{|c|c|c|c|c|c|c|c|}
\hline \multirow[t]{2}{*}{ Characteristics } & \multicolumn{2}{|c|}{$\begin{array}{c}\text { Controlled } \\
\text { hypertension }\end{array}$} & \multicolumn{2}{|c|}{$\begin{array}{l}\text { Uncontrolled } \\
\text { hypertension }\end{array}$} & \multicolumn{2}{|c|}{ Total } & \multirow[t]{2}{*}{$p$} \\
\hline & $n$ & $\%$ & $n$ & $\%$ & $n$ & $\%$ & \\
\hline \multicolumn{8}{|l|}{ Comorbidities } \\
\hline Cardiac diseases & 39 & 63.9 & 22 & 36.1 & 61 & 27.7 & 0.41 \\
\hline Stroke & 5 & 71.4 & 2 & 28.6 & 7 & 3.2 & 0.52 \\
\hline Cerebrovascular diseases & 7 & 70.0 & 3 & 30.0 & 10 & 4.6 & 0.49 \\
\hline Vascular diseases & 19 & 76.0 & 6 & 24.0 & 25 & 11.4 & 0.08 \\
\hline Kidney diseases/failure & 9 & 52.9 & 8 & 47.1 & 17 & 7.7 & 0.56 \\
\hline Metabolic syndrome & 12 & 38.7 & 19 & 61.3 & 31 & 14.1 & 0.01 \\
\hline Blood lipid disorders & 56 & 62.2 & 34 & 37.8 & 90 & 40.9 & 0.50 \\
\hline Digestive diseases & 28 & 77.8 & 8 & 22.2 & 36 & 16.4 & 0.02 \\
\hline Diabetes & 26 & 53.1 & 23 & 46.9 & 49 & 22.3 & 0.29 \\
\hline Cancer & 1 & 50.0 & 1 & 50.0 & 2 & 0.9 & 0.78 \\
\hline Spine/joint pain & 57 & 64.0 & 32 & 36.0 & 89 & 40.5 & 0.26 \\
\hline Liver diseases & 9 & 40.9 & 13 & 59.1 & 22 & 10.0 & 0.06 \\
\hline Prostate diseases & 7 & 70.0 & 3 & 30.0 & 10 & 4.6 & 0.49 \\
\hline Vestibular diseases & 5 & 83.3 & 1 & 16.7 & 6 & 2.7 & 0.23 \\
\hline \multicolumn{8}{|l|}{ Duration of disease (years) } \\
\hline $1-<2$ years & 29 & 56.9 & 22 & 43.1 & 51 & 23.2 & 0.50 \\
\hline $2-5$ years & 42 & 65.6 & 22 & 34.4 & 64 & 29.1 & \\
\hline$>5$ years & 60 & 57.1 & 45 & 42.9 & 105 & 47.7 & \\
\hline \multicolumn{8}{|l|}{ Number of antihypertensive drugs used } \\
\hline 1 & 21 & 61.8 & 13 & 38.2 & 34 & 15.5 & 0.77 \\
\hline$\geq 2$ & 110 & 59.1 & 76 & 40.9 & 186 & 84.6 & \\
\hline \multicolumn{8}{|l|}{ Overweight/obesity } \\
\hline No & 59 & 64.8 & 32 & 35.2 & 91 & 41.4 & 0.18 \\
\hline \multirow[t]{2}{*}{ Yes } & 72 & 55.8 & 57 & 44.2 & 129 & 58.6 & \\
\hline & Median & IQR & Median & IQR & Median & IQR & $p$ \\
\hline Duration of disease (years) & 5 & {$[3-10]$} & 6 & {$[2.2-10]$} & 5 & {$[3-10]$} & 0.56 \\
\hline Number of comorbidities & 2 & {$[1-3]$} & 2 & {$[1-3]$} & 2 & {$[1-3]$} & 0.72 \\
\hline Body mass index $\left(\mathrm{kg} / \mathrm{m}^{2}\right)$ & 23.4 & {$[21.8-25.2]$} & 24.0 & {$[22.3-26.1]$} & 23.7 & {$[21.9-25.4]$} & 0.02 \\
\hline Last low-density lipoprotein (LDL, mmol/L) & 2.5 & {$[1.4-3.3]$} & 2.3 & {$[1.3-3.2]$} & 2.5 & {$[1.4-3.3]$} & 0.67 \\
\hline Last high-density lipoprotein (HDL, mmol/L) & 1.3 & {$[1.1-1.6]$} & 1.2 & {$[1.1-1.4]$} & 1.2 & {$[1.1-1.6]$} & 0.18 \\
\hline Last triglyceride $(\mathrm{mmol} / \mathrm{L})$ & 1.8 & {$[1.4-2.4]$} & 2.0 & [1.3-2.9] & 1.9 & [1.4-2.8] & 0.35 \\
\hline
\end{tabular}

Male patients tended to be at higher risk of uncontrolled hypertension, which was supported by several studies in both developed and developing countries [21-23]. Literature indicated that lower concentrations of prorenin and renin contributed to the lower blood pressure among females compared to males [24, 25]. In addition, having a higher disease duration was associated with a higher risk of uncontrolled hypertension. We supposed that these patients also had a higher age, and this factor was found to be related to uncontrolled hypertension in other prior studies $[21,26]$. Nonadherence medication might not be a reasonable cause of this phenomenon since almost all patients complied with the prescribed regimes. Therefore, it is a great challenge to determine an effective approach for controlling blood pressure in these populations. These patients should also be prioritized for further interventions to reduce the burden of hypertension.

Our study was in line with prior research that increasing body mass index was a major risk factor for uncontrolled hypertension [19, 27-29]. Indeed, the dose-response relationship between body mass index and blood pressure has been fully investigated $[4,30]$. Overweight or obesity could activate the sympathetic nervous and renin-angiotensin systems as well as increase the reabsorption of kidneys via sodium retention, leading to the development of obesityrelated high blood pressure [4, 30]. Therefore, weight reduction has been proposed widely which is an effective intervention to control the blood pressure [31]. Doing physical activity or exercising regularly, thus, plays an important role in this strategy. This behavior not only reduces the bodyweight but also improves the renal function and nervous system performance as well as enhances vasoconstriction regulation [32]. Our regression model confirmed this association, showing that patients doing physical exercise frequently had a lower likelihood of having uncontrolled hypertension. Additionally, the findings of this study also underlined the benefits of cutting down smoking and stress to the improvement of blood pressure in hypertensive patients [33-35]. A prior systematic review concluded that chronic stress could increase the risk of hypertension and uncontrolled hypertension [36]. Notably, encouraging patients to prepare and carry supplies needed for hypertension when going out could reduce the risk of uncontrolled hypertension. This behavior reflects the ability for self-care in 
TABLE 3: Health behavior adherence of hypertensive patients.

\begin{tabular}{|c|c|c|c|c|c|c|c|}
\hline \multirow[t]{2}{*}{ Health behavior adherence } & \multicolumn{2}{|c|}{$\begin{array}{c}\text { Controlled } \\
\text { hypertension }\end{array}$} & \multicolumn{2}{|c|}{$\begin{array}{l}\text { Uncontrolled } \\
\text { hypertension }\end{array}$} & \multicolumn{2}{|c|}{ Total } & \multirow[t]{2}{*}{$p$} \\
\hline & $n$ & $\%$ & $n$ & $\%$ & $n$ & $\%$ & \\
\hline \multicolumn{8}{|c|}{ Take prescribed medication daily } \\
\hline No & 0 & 0.0 & 1 & 100.0 & 1 & 0.4 & 0.22 \\
\hline Yes & 131 & 59.8 & 88 & 40.2 & 219 & 99.6 & \\
\hline \multicolumn{8}{|l|}{ Follow a low-salt diet } \\
\hline No & 68 & 61.8 & 42 & 38.2 & 110 & 50.5 & 0.42 \\
\hline Yes & 61 & 56.5 & 47 & 43.5 & 108 & 49.5 & \\
\hline \multicolumn{8}{|l|}{ Follow a low-fat diet } \\
\hline No & 67 & 63.8 & 38 & 36.2 & 105 & 47.7 & 0.22 \\
\hline Yes & 64 & 55.7 & 51 & 44.4 & 115 & 52.3 & \\
\hline \multicolumn{8}{|l|}{ Exercise regularly } \\
\hline No & 17 & 51.5 & 16 & 48.5 & 33 & 15.0 & 0.31 \\
\hline Yes & 114 & 61.0 & 73 & 39.0 & 187 & 85.0 & \\
\hline \multicolumn{8}{|l|}{ Stop/cut down on smoking } \\
\hline No & 30 & 55.6 & 24 & 44.4 & 54 & 24.6 & 0.49 \\
\hline Yes & 101 & 60.8 & 65 & 39.2 & 166 & 75.5 & \\
\hline \multicolumn{8}{|l|}{ Cut down on alcohol } \\
\hline No & 24 & 58.5 & 17 & 41.5 & 41 & 18.6 & 0.88 \\
\hline Yes & 107 & 59.8 & 72 & 40.2 & 179 & 81.4 & \\
\hline \multicolumn{8}{|l|}{ Cut down on stress } \\
\hline No & 52 & 56.5 & 40 & 43.5 & 92 & 42.0 & 0.47 \\
\hline Yes & 78 & 61.4 & 49 & 38.6 & 127 & 58.0 & \\
\hline \multicolumn{8}{|c|}{ Carry supplies needed for self-care } \\
\hline No & 77 & 54.6 & 64 & 45.4 & 141 & 64.1 & 0.04 \\
\hline Yes & 54 & 68.4 & 25 & 31.7 & 79 & 35.9 & \\
\hline \multicolumn{8}{|c|}{ Overall health behavior adherence } \\
\hline No & 91 & 60.3 & 60 & 39.7 & 151 & 69.6 & 0.56 \\
\hline Yes & 37 & 56.1 & 29 & 43.9 & 66 & 30.4 & \\
\hline Adherence score & $\begin{array}{c}\text { Median } \\
29\end{array}$ & $\begin{array}{c}\text { IQR } \\
{[24-33]}\end{array}$ & $\begin{array}{c}\text { Median } \\
28\end{array}$ & $\begin{array}{c}\text { IQR } \\
{[24-32]}\end{array}$ & $\begin{array}{c}\text { Median } \\
29\end{array}$ & $\begin{array}{c}\text { IQR } \\
{[24-33]}\end{array}$ & 0.55 \\
\hline
\end{tabular}

TAвLE 4: Multivariate logistic regression to identify associated factors with uncontrolled hypertension.

\begin{tabular}{|c|c|c|c|c|}
\hline \multirow{2}{*}{ Gender } & \multicolumn{2}{|c|}{ Adjusted OR } & \multirow[t]{2}{*}{$p$ value } & \multirow[t]{2}{*}{ 95\% confidence interval } \\
\hline & \multirow[b]{2}{*}{ REF } & & & \\
\hline Male & & & & \\
\hline Female & 0.33 & 0.04 & 0.11 & 0.98 \\
\hline \multicolumn{5}{|l|}{ Using alcohol } \\
\hline No & REF & & & \\
\hline Yes & 0.39 & 0.14 & 0.11 & 1.36 \\
\hline \multicolumn{5}{|l|}{ Carry supplies needed for self-care } \\
\hline No & REF & & & \\
\hline Yes & 0.33 & 0.03 & 0.12 & 0.90 \\
\hline \multicolumn{5}{|l|}{ Follow a low-fat diet } \\
\hline No & REF & & & \\
\hline Yes & 1.94 & 0.16 & 0.77 & 4.86 \\
\hline \multicolumn{5}{|l|}{ Cut down on stress } \\
\hline No & REF & & & \\
\hline Yes & 0.35 & 0.03 & 0.14 & 0.89 \\
\hline \multicolumn{5}{|l|}{ Exercise regularly } \\
\hline No & REF & & & \\
\hline Yes & 0.23 & 0.03 & 0.06 & 0.87 \\
\hline \multicolumn{5}{|l|}{ Stop/cut down on smoking } \\
\hline No & REF & & & \\
\hline Yes & 0.21 & 0.01 & 0.06 & 0.70 \\
\hline \multicolumn{5}{|l|}{ Overall health behavior adherence } \\
\hline No & REF & & & \\
\hline Yes & 3.02 & 0.07 & 0.92 & 9.88 \\
\hline Duration of disease (years) & 1.07 & 0.03 & 1.01 & 1.14 \\
\hline Body mass index $\left(\mathrm{kg} / \mathrm{m}^{2}\right)$ & 1.23 & 0.01 & 1.05 & 1.45 \\
\hline Last high-density lipoprotein (HDL, mmol/L) & 0.73 & 0.06 & 0.53 & 1.02 \\
\hline Last triglyceride $(\mathrm{mmol} / \mathrm{L})$ & 1.37 & 0.06 & 0.99 & 1.88 \\
\hline
\end{tabular}


patients, which is a vital component for effective blood pressure management [19, 37].

Several major limitations should be acknowledged. First, data from this study were obtained via a cross-sectional design, which did not allow us to measure the causal relationship between uncontrolled hypertension among hypertensive patients and its related factors. Second, our sample was recruited by using a convenient sampling method in one hospital; therefore, the result of this study should be cautious about being applied in other settings. Third, several variables such as home blood pressure monitoring, class of drugs, or clinical inertia therapeutic were not included in this study. Further research should be warranted to investigate associations between these factors and uncontrolled blood pressure.

\section{Conclusions}

This study reveals that uncontrolled hypertension was common among hypertensive patients in Vietnam. Improving self-care capacity and encouraging healthy behaviors are critically important to control blood pressure, particularly among patients who were males and had high disease duration and body mass index.

\section{Data Availability}

The data used to support the findings of the study are available from the corresponding author upon request.

\section{Conflicts of Interest}

The authors declare that there are no conflicts of interest regarding the publication of this paper.

\section{References}

[1] B. Sakboonyarat, R. Rangsin, A. Kantiwong, and M. Mungthin, "Prevalence and associated factors of uncontrolled hypertension among hypertensive patients: a nationwide survey in Thailand," BMC Research Notes, vol. 12, no. 1, p. 380, 2019.

[2] K. T. Mills, J. D. Bundy, T. N. Kelly et al., "Global disparities of hypertension prevalence and control," Circulation, vol. 134, no. 6, pp. 441-450, 2016.

[3] A. Dzudie, A. P. Kengne, W. F. Muna et al., "Prevalence, awareness, treatment and control of hypertension in a selfselected sub-Saharan African urban population: a cross-sectional study," BMJ Open, vol. 2, no. 4, 2012.

[4] P. K. Whelton, R. M. Carey, W. S. Aronow et al., "2017 ACC/ AHA/AAPA/ABC/ACPM/AGS/APhA/ASH/ASPC/NMA/ PCNA guideline for the prevention, detection, evaluation, and management of high blood pressure in adults: executive summary: a report of the American college of cardiology/ American heart association task force on clinica ," Journal of the American Society of Hypertension, vol. 12, no. 8, pp. 579-e573, 2018.

[5] Z. Wang, Z. Chen, L. Zhang et al., "Status of hypertension in China," Circulation, vol. 137, no. 22, pp. 2344-2356, 2018.

[6] S. Wang, P. Puska, B. Norrving, and W. H. Organization, Global Atlas on Cardiovascular Disease Prevention and
Control, World Health Organization, Geneva, Switzerland, 2011.

[7] T. M. Abegaz, O. A. Abdela, A. S. Bhagavathula, and F. S. Teni, "Magnitude and determinants of uncontrolled blood pressure among hypertensive patients in Ethiopia: hospital based observational study," Pharmacy Practice, vol. 16, no. 2, p. 1173, 2018.

[8] A. B. Olomu, V. Gourineni, J. L. Huang et al., "Rate and predictors of blood pressure control in a federal qualified health center in Michigan: a huge concern?" The Journal of Clinical Hypertension, vol. 15, no. 4, pp. 254-263, 2013.

[9] D. F. Teshome, A. F. Demssie, and B. M. Zeleke, "Determinants of blood pressure control amongst hypertensive patients in Northwest Ethiopia," PLoS ONE, vol. 13, no. 5, Article ID e0196535, 2018.

[10] D. Zhou, B. Xi, M. Zhao, L. Wang, and S. P. Veeranki, "Uncontrolled hypertension increases risk of all-cause and cardiovascular disease mortality in US adults: the NHANES III linked mortality study," Scientific Report, vol. 8, no. 1, p. $9418,2018$.

[11] M. Lanti, P. E. Puddu, O. T. Vagnarelli et al., "Antihypertensive treatment is not a risk factor for major cardiovascular events in the gubbio residential cohort study," Journal of Hypertension, vol. 33, no. 4, pp. 736-744, 2015.

[12] Vietnam Ministry of Health, "Joint annual health review 2014: strengthening prevention and control of non-communicable disease," Vietnam Ministry of Health, Hanoi, Vietnam, 2015.

[13] L. Meiqari, D. Essink, P. Wright, and F. Scheele, "Prevalence of hypertension in Vietnam: a systematic review and metaanalysis," Asia Pacific Journal of Public Health, vol. 31, no. 2, pp. 101-112, 2019.

[14] H. Van Minh, N. L. Viet, C. T. Sinh et al., "Blood pressure screening during the may measurement month 2017 programme in vietnam-south-east Asia and australasia," European Heart Journal Supplements, vol. 21, no. Supplement_D, pp. D127-d129, 2019.

[15] R. L. Tuan, R. D. Hays, C. D. Sherbourne et al., "Recall of recommendations and adherence to advice among patients with chronic medical conditions," Archives of Internal Medicine, vol. 153, no. 16, pp. 1869-1878, 1993.

[16] R. Choudhary, S. M. Sharma, V. Kumari, and D. Gautam, "Awareness, treatment adherence and risk predictors of uncontrolled hypertension at a tertiary care teaching hospital in Western India," Indian Heart Journal, vol. 68, no. Suppl 2, pp. S251-s252, 2016.

[17] O. V. Adeniyi, P. Yogeswaran, B. Longo-Mbenza, and D. Ter Goon, "Uncontrolled hypertension and its determinants in patients with concomitant type 2 diabetes mellitus (T2DM) in rural South Africa," PLoS ONE, vol. 11, no. 3, Article ID e0150033, 2016.

[18] T. Kika, F. Lepira, P. Kayembe et al., "Uncontrolled hypertension among patients managed in primary healthcare facilities in Kinshasa, Democratic Republic of the Congo," Cardiovascular Journal of Africa, vol. 27, no. 6, pp. 361-366, 2016.

[19] G. B. Gebremichael, K. K. Berhe, and T. M. Zemichael, "Uncontrolled hypertension and associated factors among adult hypertensive patients in ayder comprehensive specialized hospital, Tigray, Ethiopia, 2018," BMC Cardiovascular Disorders, vol. 19, no. 1, p. 121, 2019.

[20] F. S. Sarfo, L. M. Mobula, G. Burnham et al., "Factors associated with uncontrolled blood pressure among ghanaians: evidence from a multicenter hospital-based study," PLoS ONE, vol. 13, no. 3, Article ID e0193494, 2018. 
[21] D. J. Hyman and V. N. Pavlik, "Characteristics of patients with uncontrolled hypertension in the United States," New England Journal of Medicine, vol. 345, no. 7, pp. 479-486, 2001.

[22] B. M. Egan, Y. Zhao, R. N. Axon, W. A. Brzezinski, and K. C. Ferdinand, "Uncontrolled and apparent treatment resistant hypertension in the United States, 1988 to 2008," Circulation, vol. 124, no. 9, pp. 1046-1058, 2011.

[23] A. Khosravi, B. Pourheidar, H. Roohafza et al., "Evaluating factors associated with uncontrolled hypertension: isfahan cohort study, Iran," ARYA Atherosclerosis, vol. 10, no. 6, pp. 311-318, 2014.

[24] K. Sandberg and H. Ji, "Sex differences in primary hypertension," Biology of Sex Differences, vol. 3, no. 1, p. 7, 2012.

[25] A. H. Danser, F. H. Derkx, M. A. Schalekamp, H. W. Hense, G. A. Riegger, and H. Schunkert, "Determinants of interindividual variation of renin and prorenin concentrations: evidence for a sexual dimorphism of (pro)renin levels in humans," Journal of Hypertension, vol. 16, no. 6, pp. 853-862, 1998.

[26] M. A. Khanam, W. Lindeboom, A. Razzaque, L. Niessen, W. Smith, and A. H. Milton, "Undiagnosed and uncontrolled hypertension among the adults in rural Bangladesh," Journal of Hypertension, vol. 33, no. 12, pp. 2399-2406, 2015.

[27] T. Goverwa, N. Masuka, M. Tshimanga et al., "Uncontrolled hypertension among hypertensive patients on treatment in lupane district, Zimbabwe, 2012," BMC Research Notes, vol. 7, no. 1, p. 703, 2014.

[28] L. Yang, X. Xu, J Yan et al., "Analysis on associated factors of uncontrolled hypertension among elderly hypertensive patients in Southern China: a community-based, cross-sectional survey," BMC Public Health, vol. 14, p. 903, 2014.

[29] B. Tesfaye, D. Haile, B. Lake, T. Belachew, T. Tesfaye, and H. Abera, "Uncontrolled hypertension and associated factors among adult hypertensive patients on follow-up at Jimma university teaching and specialized hospital: cross-sectional study," Research Reports in Clinical Cardiology, vol. 8, p. 21, 2017.

[30] S.-Z. Jiang, W. Lu, X.-F. Zong, H.-Y. Ruan, and Y. Liu, "Obesity and hypertension," Experimental and Therapeutic Medicine, vol. 12, no. 4, pp. 2395-2399, 2016.

[31] J. E. Neter, B. E. Stam, F. J. Kok, D. E. Grobbee, and J. M. Geleijnse, "Influence of weight reduction on blood pressure," Hypertension, vol. 42, no. 5, pp. 878-884, 2003.

[32] K. M. Diaz and D. Shimbo, "Physical activity and the prevention of hypertension," Current Hypertension Reports, vol. 15, no. 6, pp. 659-668, 2013.

[33] J. Sanz, M. P. García-Vera, R. Espinosa, M. Fortún, I. Magán, and J. Segura, "Psychological factors associated with poor hypertension control: differences in personality and stress between patients with controlled and uncontrolled hypertension," Psychological Reports, vol. 107, no. 3, pp. 923-938, 2010.

[34] S. E. McNagny, J. S. Ahluwalia, W. S. Clark, and K. A. Resnicow, "Cigarette smoking and severe uncontrolled hypertension in inner-city African Americans," The American Journal of Medicine, vol. 103, no. 2, pp. 121-127, 1997.

[35] X. Liu and J. B. Byrd, "Cigarette smoking and subtypes of uncontrolled blood pressure among diagnosed hypertensive patients: paradoxical associations and implications," American Journal of Hypertension, vol. 30, no. 6, pp. 602-609, 2017.

[36] F. Sparrenberger, F. T. Cichelero, A. M. Ascoli et al., "Does psychosocial stress cause hypertension? a systematic review of observational studies," Journal of Human Hypertension, vol. 23, no. 1, pp. 12-19, 2009.
[37] E. Lee and E. Park, "Self-care behavior and related factors in older patients with uncontrolled hypertension," Contemporary Nurse, vol. 53, no. 6, pp. 607-621, 2017. 